\title{
Incorporation of iron nanoparticles into clinoptilolite and its application for the removal of cationic and anionic dyes
}

\author{
Muath Nairat $^{a}$, Talal Shahwan ${ }^{a, *}$, Ahmet E. Eroğlu $^{b}$, Harald Fuchs ${ }^{c}$ \\ a Department of Chemistry, Birzeit University, Birzeit, West Bank, Palestine \\ ${ }^{\mathrm{b}}$ Department of Chemistry, Izmir Institute of Technology, Urla 35430, Izmir, Turkey \\ ' Physikalisches Institut E' Center for Nanotechnology (CeNTech), Universität Münster, Germany
}

\section{A R T I C L E I N F O}

\section{Article history:}

Received 31 January 2014

Received in revised form 17 May 2014

Accepted 20 May 2014

Available online 27 May 2014

\section{Keywords:}

Clinoptilolite

Iron nanoparticles

Methyl orange

Methylene blue

\begin{abstract}
A B S T R A C T
This study reports the preparation of composite sorbents of iron nanoparticles (nZVI) and clinoptilolite at various iron/clinoptilolite ratios. The composites were characterized using various characterization techniques. The material was used for the removal of methylene blue (MB) and methyl orange (MO) as model cationic and anionic dyes. The experiments investigated the effects of time, loading, initial $\mathrm{pH}$, reusability, and temperature on the removal process. According to the results, Cl-nZVI showed fast and quantitative removal over a wide range of concentrations. The removal process was endothermic in nature, and the composite demonstrated reusability for several trials.
\end{abstract}

(c) 2014 The Korean Society of Industrial and Engineering Chemistry. Published by Elsevier B.V. All rights reserved.

\section{Introduction}

Nano-scale zero valent iron (nZVI) is continuing to gain interest as a powerful tool for soil and water remediation over the last two decades $[1,2]$. The material has been proven to possess high potential toward the removal of various organic and inorganic pollutants from aqueous solutions such as transition and heavy metals [3-5], chlorinated organic compounds [6-8], nitrates [9] and others. The use of nZVI forms an immense enhancement over the use of conventional iron powders [10], which were proven for their removal efficiency of various pollutants and are being applied as filling materials in industrial scale remediation facilities known as permeable reactive barriers [11,12]. The enhancement is attributed primarily to the large surface to volume ratio of nZVI, which results in huge increase of its surface reactivity.

The effluents of dyestuff, printing, textiles, paper, leather, cosmetics and other various industries contain a significant part of waste dyes that require a crucial removal step, as most of them are composed of aromatic related compounds that cannot be easily biodegraded or photodegraded [13]. Water containing low concentrations of dyes, even as low as $1.0 \mathrm{mg} / \mathrm{L}$, may be regarded as unfit for human consumption due to the imparted color from the

\footnotetext{
Abbreviations: nZVI, nano-scale zero valent iron; Cl-nZVI, clinoptilolite supported nano-scale zero valent iron; MO, methyl orange; MB, methylene blue.

* Corresponding author. Tel.: +970 22982040.

E-mail addresses: tshahwan@birzeit.edu, tshahwan08@gmail.com (T. Shahwan).
}

dye [14]. Furthermore, these dyes can exhibit toxicity on the aquatic life and may bring about severity on their life span by reducing the amount of the transmitted light through water [15]. So far, large part of the dyes has been considered for its toxicity, mutagenicity and carcinogenicity [16]. In this study, methylene blue and methyl orange were employed in the dye removal experiments. Methylene blue is a heterocyclic aromatic thiazine compound with the molecular formula of $\mathrm{C}_{16} \mathrm{H}_{18} \mathrm{~N}_{3} \mathrm{~S}^{+} \mid \mathrm{Cl}^{-}$. Methyl orange is an anionic azo dye with the molecular formula of $\mathrm{Na}^{+} \mid \mathrm{C}_{14} \mathrm{H}_{14} \mathrm{~N}_{3} \mathrm{O}_{3} \mathrm{~S}^{-}$. This dye has been studied by many researchers as a model of an azo dye, wherein azo dyes stand for about half the dye usage in industry [17].

The removal of dyes from water by means of adsorption has been tested on various adsorbents such as activated carbon, minerals, clays, polymers and various natural adsorbents [18-22]. Since iron nanoparticles showed promising water remediation features, it was also tested in the removal of various dyes [23,24]. However, one of the obstacles associated with the application of nZVI originates from the tendency of nanoparticles to aggregate into large chains, reaching several micrometers in size. This tendency is due to the strong magnetic moments of iron itself, but is also enhanced greatly in aqueous media, in which the aggregates can amount to tens of micrometers in size [4]. The use of support materials during the synthesis of nZVI was tried as a means of limiting the aggregation of nZVI. For this purpose, several solid supports were previously used such as natural clays [25,26], alumina [27], exfoliated graphite [28], chitosan [29] and zeolite [30]. 
In this study, iron nanoparticles supported on clinoptilolite $(\mathrm{Cl}-$ nZVI) were prepared in different iron/clinoptilolite mass ratios. Clinoptilolite is a widely available natural zeolite which enjoys a large surface area, structural, chemical and thermal stability. The composite materials were characterized using various techniques including scanning electron microscopy (SEM), transmission electron microscopy (TEM), energy dispersive X-ray spectroscopy (EDX), X-ray diffraction (XRD), X-ray photoelectron spectroscopy (XPS), and Brunauer-Emmett-Teller (BET) specific surface area. The Cl-nZVI composites were subsequently applied for the removal of methylene blue (MB) and methyl orange (MO), used as models for cationic and anionic dyes, respectively. The dye removal process was tested over a wide range of contact periods to assess the kinetic behavior of the dye removal. Moreover, the removal of both dyes was tested over various initial dye loadings to investigate the extents of their removal. The effects of temperature, $\mathrm{pH}$, and reusability of the composite material were also investigated. The performance of $\mathrm{Cl}-\mathrm{nZVI}$ was compared with those of nZVI and clinoptilolite.

\section{Materials and experimental methods}

\section{Preparation of nZVI and Cl-nZVI}

Iron nanoparticles (nZVI) and the composite of iron nanoparticles supported on clinoptilolite ( $\mathrm{Cl}-\mathrm{nZVI}$ ) were prepared using the borohydride reduction method in accordance with previous reports [3,26]. Cl-nZVI was prepared in 1:1 clinoptilolite:nZVI mass ratios by dissolving $5.34 \mathrm{~g}$ of $\mathrm{FeCl}_{2} \cdot 4 \mathrm{H}_{2} \mathrm{O}$ (Aldrich 22029-9) in $25.0 \mathrm{~mL} 4: 1$ ethanol:water solution. Subsequently, $1.5 \mathrm{~g}$ of clinoptilolite (obtained from Inamarble Company) was added to the solution and mixed on a magnetic stirrer for $15 \mathrm{~min}$. $\mathrm{NaBH}_{4}$ (Merck 8.06373.0025) solution was prepared separately by dissolving $2.54 \mathrm{~g}$ in $70.0 \mathrm{~mL}$ deionized water, then it was added using a buret to the iron-clinoptilolite solution under continuous stirring at a constant addition rate of $0.5 \mathrm{~mL} / \mathrm{s}$. After borohydride addition, the solution was kept under continuous stirring for another $15 \mathrm{~min}$ then filtered under suction and washed 3 times with absolute ethanol. Finally, the Cl-nZVI composite was dried in the oven at $90^{\circ} \mathrm{C}$ for $6 \mathrm{~h}$ and stored in amber glass bottles in desiccator. The same procedure was followed to prepare $2: 1,3: 1$ and 5:1 clinoptilolite:nZVI ratios, using $3.0 \mathrm{~g}, 4.5 \mathrm{~g}$, and $7.5 \mathrm{~g}$ of clinoptilolite, respectively.

\section{Preparation of methylene blue and methyl orange solutions}

$1000 \mathrm{mg} / \mathrm{L} \mathrm{MB}$ (Certistain 15943) and MO (Aldrich 140910) stock solutions were prepared using deionized water. Serial dilutions were made using deionized water to prepare solutions with lower concentrations. The concentrations were determined at the corresponding $\lambda_{\max }$ using UV-visible spectrophotometry.

\section{Dye removal experiments}

All dye removal experiments were performed under atmospheric pressure using poly propylene falcon tubes placed under non disturbed (without shaking) conditions in a thermostat water bath adjusted at $25^{\circ} \mathrm{C}$, and the $\mathrm{pH}$ of solutions was kept in most experiments at neutrality without modifications unless stated otherwise. The dye concentration was determined using UVvisible spectrophotometry (Varian Carry 50 Spectrophotometer) at $\lambda_{\max }=665 \mathrm{~nm}$ for $\mathrm{MB}$ and $\lambda_{\max }=465 \mathrm{~nm}$ for $\mathrm{MO}$ from prepared standard calibration curves of $1.0-10.0 \mathrm{mg} / \mathrm{L} \mathrm{MB}$ and $1.0-25.0 \mathrm{mg} /$ L MO.

To study the dye removal kinetics, $0.100 \mathrm{~g}$ of the adsorbent (clinoptilolite, nZVI, and Cl-nZVI) was added to $25.0 \mathrm{~mL}$ of the dye at initial concentrations of $10.0 \mathrm{mg} / \mathrm{L}$ and $100.0 \mathrm{mg} / \mathrm{L}$. At the end of contact periods, the solutions were separated from the solids by centrifugation and simple decantation. The concentrations of the solutions were subsequently determined using UV-visible spectrophotometry. Parallel experiments were carried out without introducing any adsorbent in order to check for side dye adsorption on internal tube surface. Due to different dye removal potential of each adsorbent, the kinetic assessment was repeated with different contact times for each adsorbent as described later in the results.

In order to determine the effect of dye concentration on the extent of removal, $0.100 \mathrm{~g}$ of the adsorbent (clinoptilolite, nZVI or Cl-nZVI) was added to $25.0 \mathrm{~mL}$ dye solutions at different concentrations, and was kept in contact without shaking in the water bath till equilibrium has been achieved. The same experiments were also repeated at $50{ }^{\circ} \mathrm{C}$ to determine the effect of temperature on the dye removal process. The contact time (equilibrium time) and the dye concentrations were different for

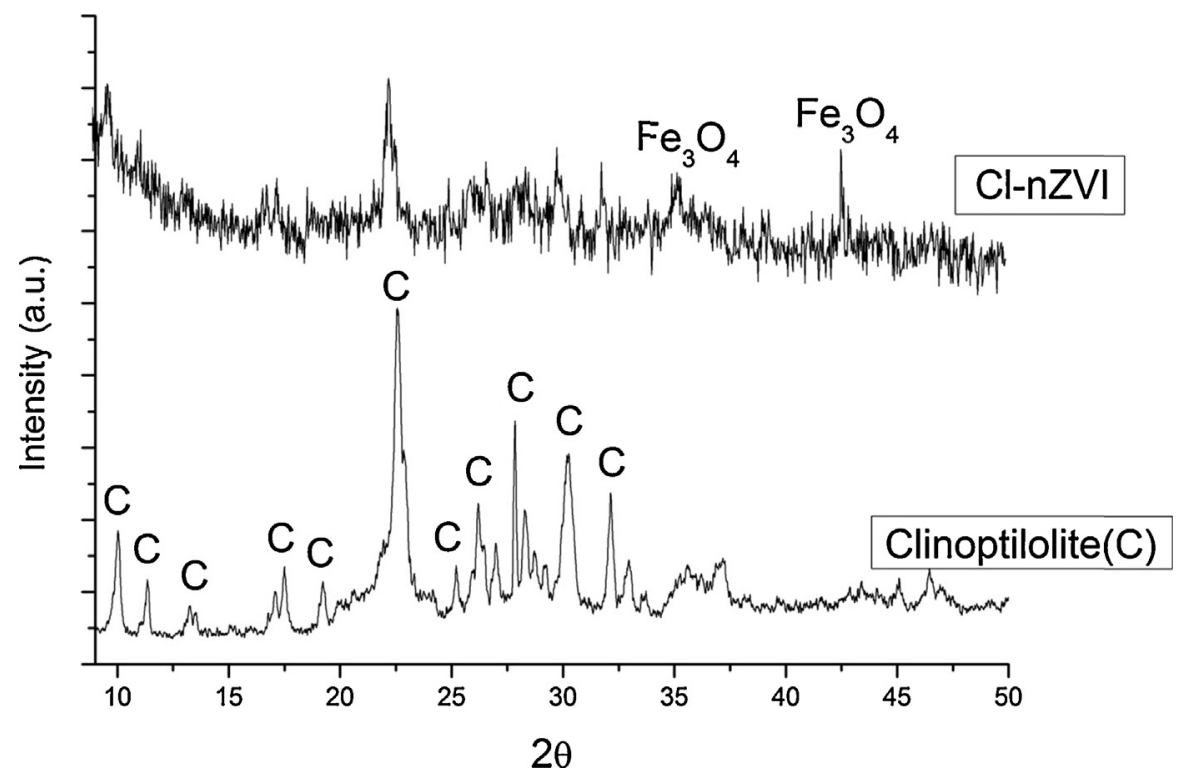

Fig. 1. XRD patterns of clinoptilolite and the composite Cl-nZVI. 


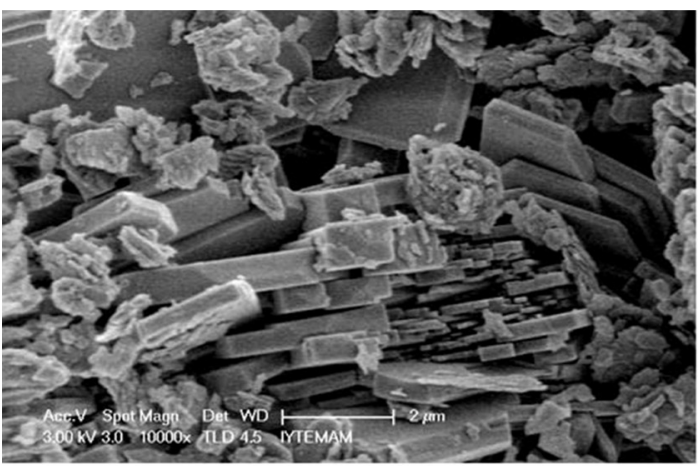

A
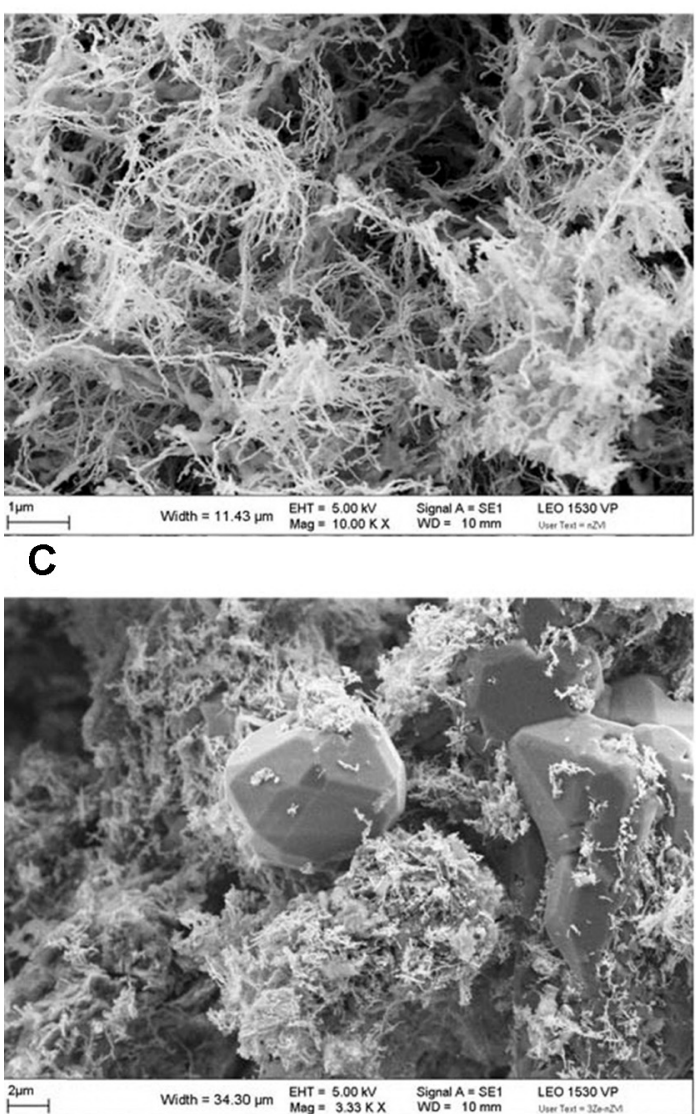

E

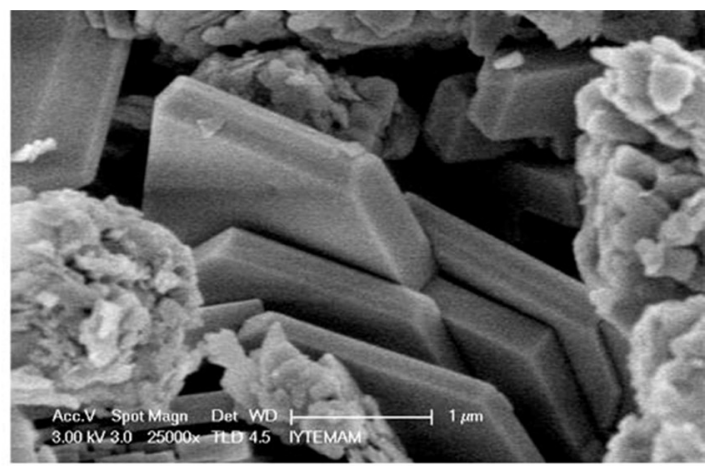

B

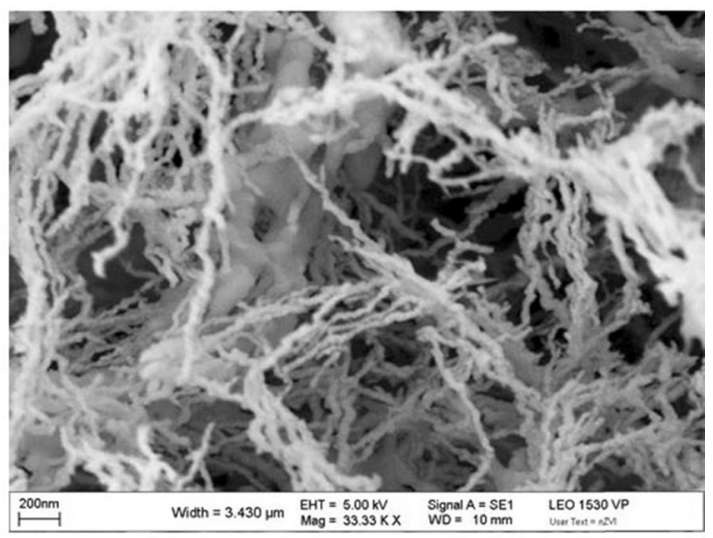

D

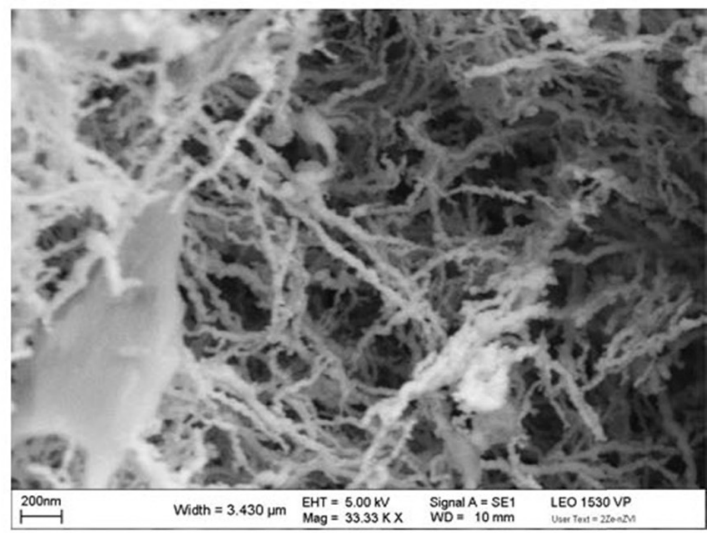

$\mathbf{F}$

Fig. 2. SEM images of clinoptilolite (A and B), nZVI (C and D) and Cl-nZVI (E and F).

each adsorbent since each adsorbent exhibits its unique dye removal potential.

To assess and compare the longevity and reusability of nZVI and $\mathrm{Cl}-\mathrm{nZVI}$ in the dye removal process, $0.100 \mathrm{~g}$ of each adsorbent was kept in contact for $1 \mathrm{~h}$ with $25.0 \mathrm{~mL}$ of each dye at $10.0 \mathrm{mg} / \mathrm{L}$ initial concentration under the experimental conditions. The solids were then carefully filtered from the dye solution and reused in the removal of other $25.0 \mathrm{~mL}$ aliquots of $10.0 \mathrm{mg} / \mathrm{L}$ dye solution. The same process was repeated for 7 successive trials.

To account for the effect of initial $\mathrm{pH}$ on the dye removal process, $0.100 \mathrm{~g}$ of nZVI or Cl-nZVI was introduced to $25.0 \mathrm{~mL}$ of $100.0 \mathrm{mg} / \mathrm{L}$ dye solution, and then the $\mathrm{pH}$ was adjusted immediately to $3,5,7$ and 9 using either $0.1 \mathrm{M} \mathrm{HCl}$ or $0.1 \mathrm{M} \mathrm{NaOH}$ and kept in contact for $1 \mathrm{~h}$. The final $\mathrm{pH}$ of the solutions was measured along with the dye concentration.

\section{Characterization of clinoptilolite, nZVI and Cl-nZVI}

Clinoptilolite, nZVI and Cl-nZVI were characterized using SEM, EDX, TEM, XPS, XRD and BET techniques.

The SEM/EDX analysis was realized using Gemini LEO 1530 VP instrument. The solid samples were first sprinkled onto adhesive carbon tapes supported on metallic disks. SEM and back-scattered SEM images of the sample surface were recorded at different magnifications. The EDX analysis was realized in integrated analysis mode, in which a total area of about 1$3 \mathrm{~mm}^{2}$ on the surface was scanned and the elemental content was revealed.

The TEM analyses for nZVI and Cl-nZVI were carried out using ZEISS Libra 200FE instrument. The instrument was operated at $200 \mathrm{kV}$. Each sample was dispersed in chloroform by means of an ultrasonic shaker path, and subsequently few drops of the 


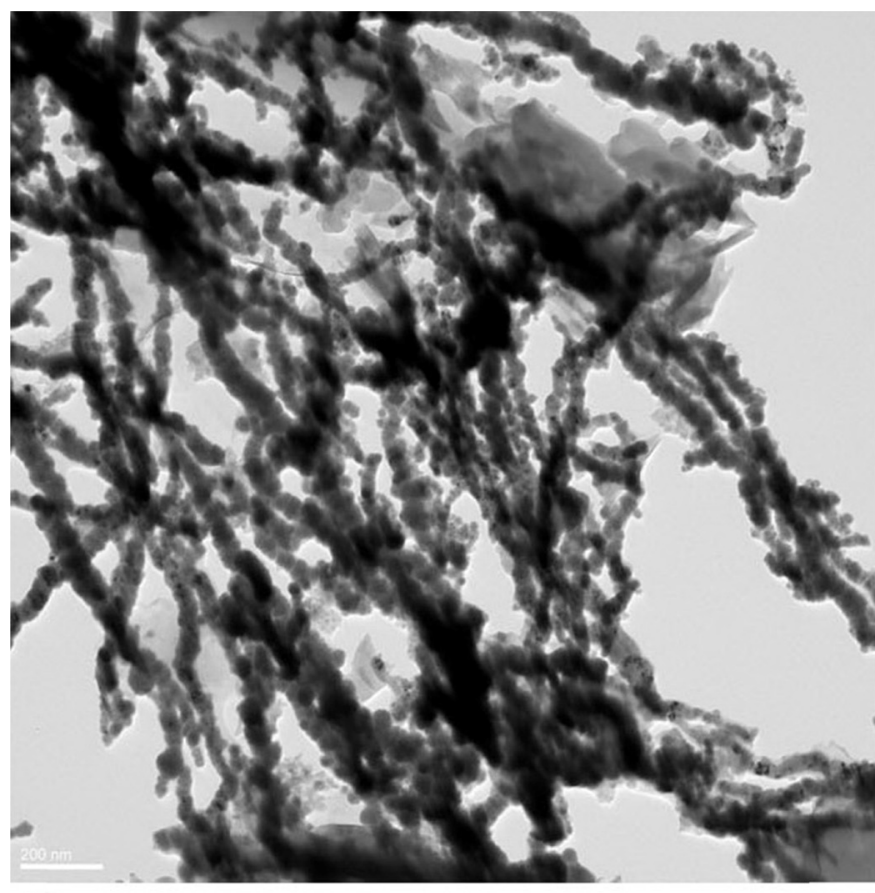

A

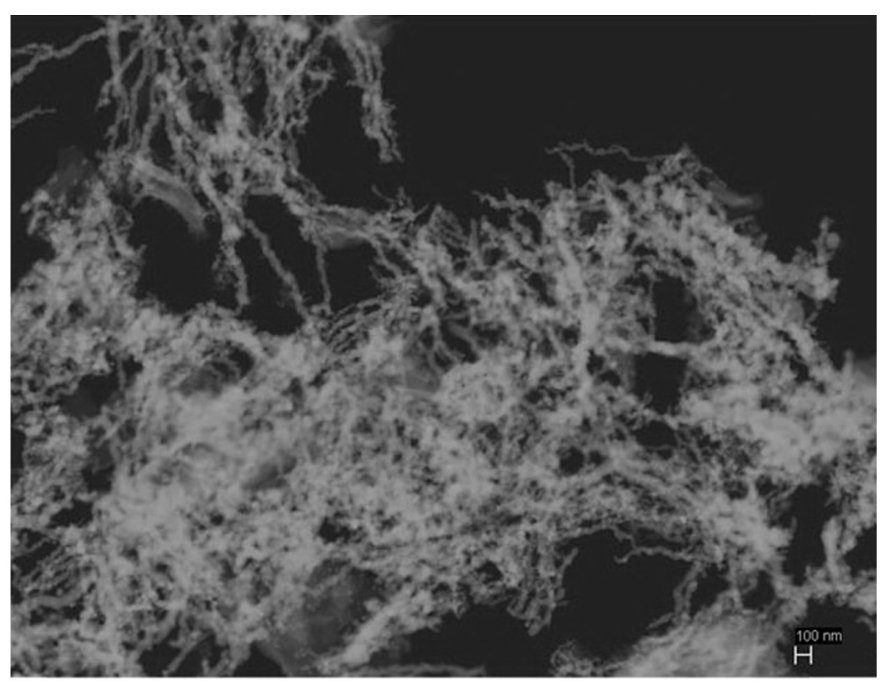

B

Fig. 3. Cl-nZVI TEM image (A) and STEM image (B).

suspension were placed on a holey carbon film supported on copper substrate. TEM and STEM images were recorded at different magnification and EDX mappings were carried for STEM images.
The XPS analysis for nZVI and Cl-nZVI was performed using VG Scientific ESCALAB 250 operating at Al K $\alpha$ X-ray source. The samples were mounted onto instrument sample holder and data acquisition was realized under high vacuum with $30 \mathrm{eV}$ pass energy and $100 \mathrm{~ms}$
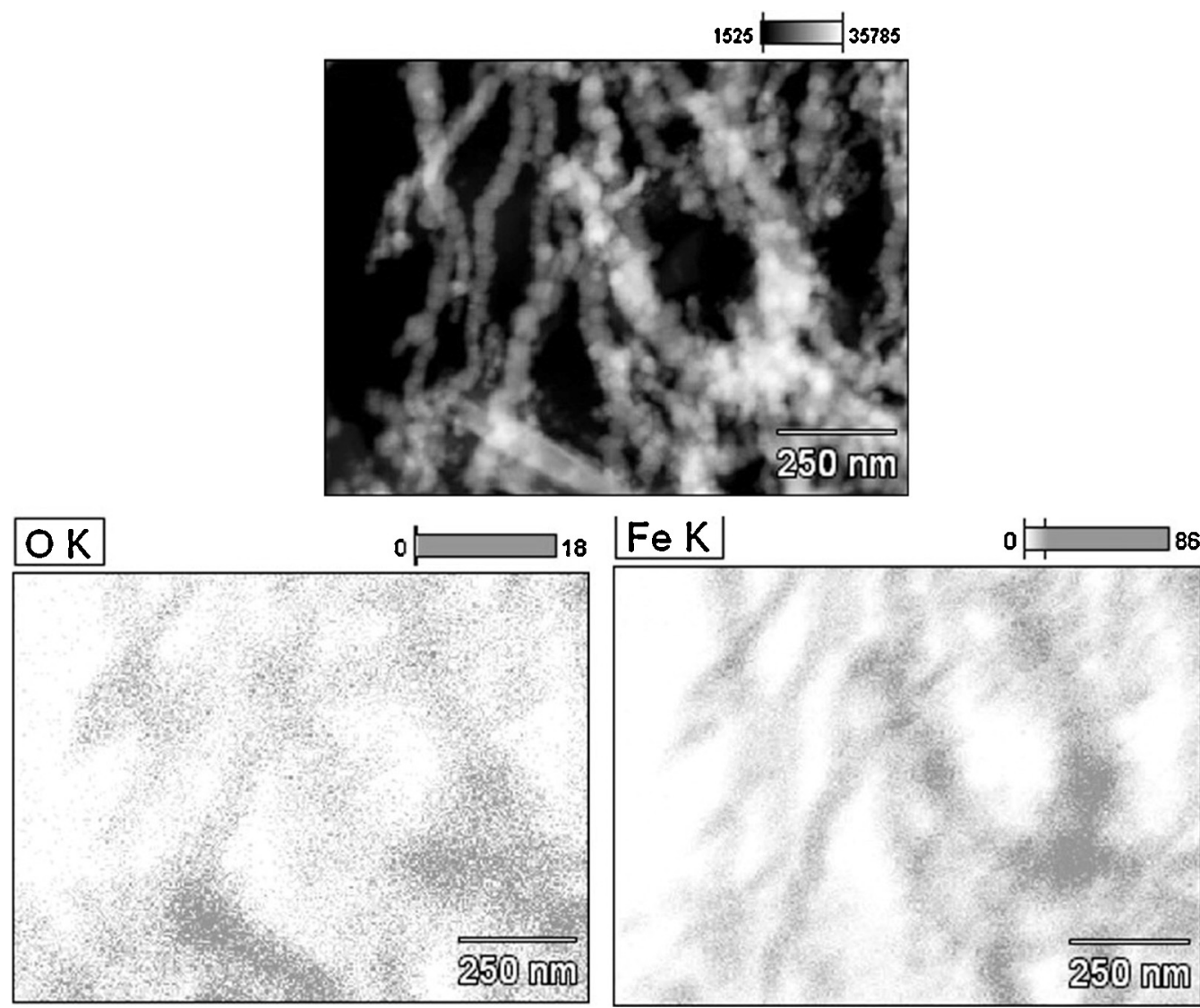

Fig. 4. STEM image of Cl-nZVI and elemental mappings for $\mathrm{O}$ and Fe. 
dwell time. The binding energy of the collected photoelectrons was calibrated using the adventurous $\mathrm{C} 1 \mathrm{~s}$ peak at $284.6 \mathrm{eV}$ binding energy.

XRD diagrams were recorded using Philips X'Pert Pro diffractometer (PANalytical), using the copper $K \alpha$-line $(\lambda=1.54060 \AA)$, at $40 \mathrm{kV}, 30 \mathrm{~mA}$ in line-focus mode. The diffractometer was set up with a PW3050/6x goniometer and data were collected from $2 \theta=5^{\circ}$ to $70^{\circ}$, with a step size of $0.02^{\circ}$ and a dwell time of $1 \mathrm{~s}$ per step.

BET surface area was determined by the BET- $\mathrm{N}_{2}$ method using a Micromeritics Gemini 5 instrument. The samples were degassed for $3 \mathrm{~h}$ at $353 \mathrm{~K}$ using $\mathrm{N}_{2}$ gas.

\section{Results and discussion}

\section{Characterization of clinoptilolite, nZVI and Cl-nZVI}

XRD was used to reveal the mineralogical content of clinoptilolite zeolite. According to the results (Fig. 1), the material is primarily composed of clinoptilolite, which is the most widely found form of natural zeolite. The XRD diagram of Cl-nZVI in the same figure indicates the presence of $\mathrm{Fe}_{3} \mathrm{O}_{4}$, as it appears from the features at $2 \theta$ of 35.5 and 43 , which corresponds to $h k l$ values of 311 and 400 . The primary peak of $\mathrm{Fe}^{0}$ that is normally observed around $2 \theta$ of 44.8 cannot be clearly distinguished in the XRD pattern, although its presence was verified from XPS results and SEM images, as discussed next.

As seen in Fig. 2, SEM images of clinoptilolite (A and B) show tabular and coffin like morphologies typical for clinoptilolite. The edge sizes appear to range from 1 to $5 \mu \mathrm{m}$. The presence of some irregular globular shaped species along with the clinoptilolite crystals can also be seen in the SEM images indicating the presence of some mineralogical impurities. The SEM images of nZVI (Fig. 2C and D) show its characteristic chain like morphology. The particle size of individual nanoparticles ranges between 40 and $60 \mathrm{~nm}$. SEM images of the composite Cl-nZVI material are displayed in Fig. 2E and $\mathrm{F}$. The images show that nZVI morphology in the composite resembles that of pure nZVI. Most of iron nanoparticle chains appear to grow in between the clinoptilolite crystals while others seem to cover the surface of these crystals.

The chain-like morphology, characteristic for nZVI, is also revealed by TEM and STEM images of a Cl-nZVI sample (Fig. 3). EDX maps of Fe and $\mathrm{O}$ obtained from a Cl-nZVI domain rich in nZVI are shown in Fig. 4. The sharper Fe signals compared with $\mathrm{O}$ are indicative that $\mathrm{Fe}$ is more dominant in the structure of the nanoparticles, which is a typical consequence of the core-shell structure of nZVI, as the core contains $\mathrm{Fe}^{0}$ solely, while the shell is composed of iron (hydr)oxides [31].

The EDX spectrum of clinoptilolite (Fig. 5A) reveals its elemental composition. The mineral is composed mainly of $\mathrm{Si}$, $\mathrm{Al}$ and $\mathrm{O}$. The EDX spectrum of $\mathrm{Cl}-\mathrm{nZVI}$ composite (Fig. 5B) clearly shows a distinct Fe peak. Moreover, EDX analysis for various $\mathrm{Cl}-$ nZVI composites (Fig. 5C and D) with $1: 1,2: 1,3: 1$ and 5:1 clinoptilolite:iron ratios (here and thereafter referred to as $1 \mathrm{Cl}$ nZVI, 2Cl-nZVI, 3Cl-nZVI and 5Cl-nZVI, respectively) shows a decrease in elemental surface Fe content and an increase in $\mathrm{Si}$ content as the amount of clinoptilolite increases. The weight percentages of main elements in clinoptilolite, nZVI and various $\mathrm{Cl}$ nZVI composites are provided in Table 1 . The table shows also the elemental content of a $3 \mathrm{Cl}-\mathrm{nZVI}$ sample after being used in the dye removal. The $\mathrm{Fe} / \mathrm{O}$ ratio in the $3 \mathrm{Cl}-\mathrm{nZVI}$ sample decreases from 1.7 to 1.0 , which is a consequence of the oxidation of iron. The oxidation of iron nanoparticles leads to agglomeration of iron and loss in the nZVI chain-like morphology. However, the presence of the clinoptilolite crystals in the composite is believed to limit the agglomeration by forming physical barriers among the dispersed chains of iron nanoparticles.

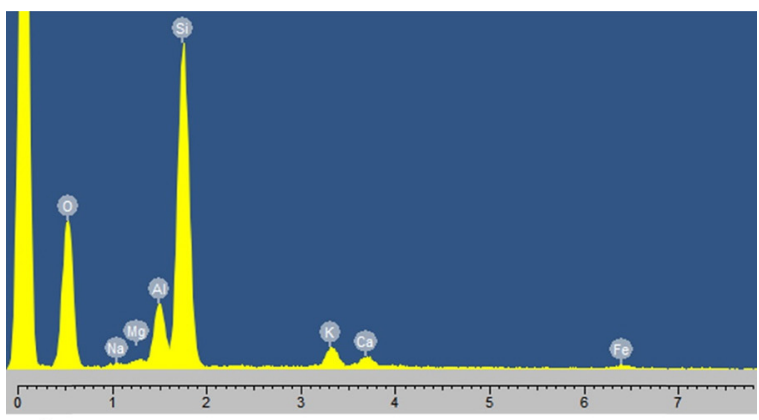

A

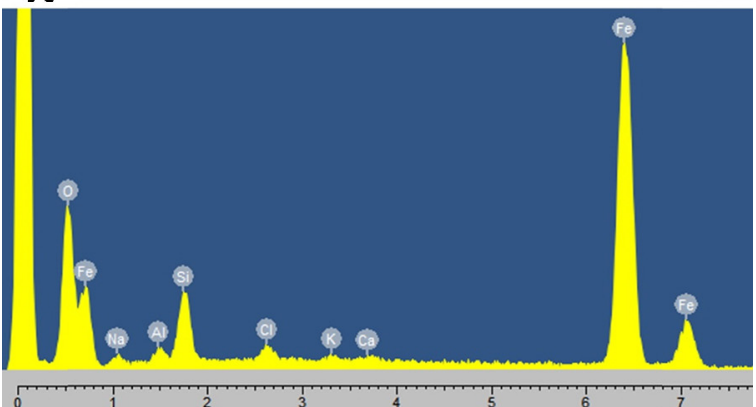

B

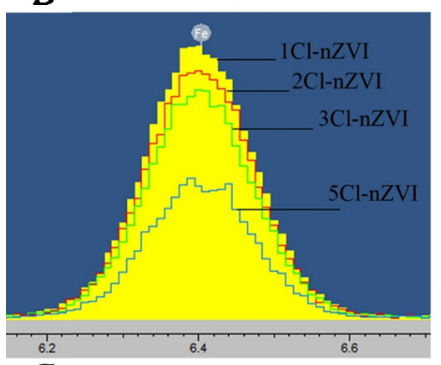

C

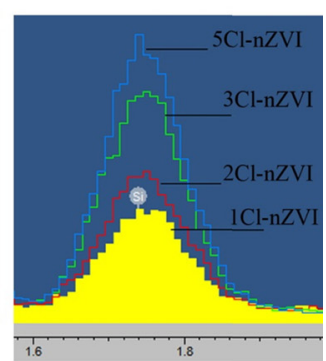

D
Fig. 5. EDX spectra of clinoptilolite (A) and Cl-nZVI (B), Fe peaks (C) and Si peaks (D) of $\mathrm{Cl}-\mathrm{nZVI}$ composites with different clinoptilolite:iron ratios.

XPS was also used to elucidate the surface composition of $\mathrm{Cl}$ nZVI. The elemental composition of the surface is shown in a typical XPS spectrum in Fig. 6. Enhanced scan over the characteristic Fe 2 p peaks is presented in the inset of Fig. 6 . The features appearing at $724.9 \mathrm{eV}, 719.5 \mathrm{eV}$ and $710.5 \mathrm{eV}$ peaks correspond to the binding energies of Fe $2 \mathrm{p} 1 / 2$, shake-up satellite $2 \mathrm{p} 3 / 2$, and $2 \mathrm{p} 3 / 2$, respectively. The peaks suggest that iron shell is composed mainly of iron oxides and iron oxyhydroxides [25]. The peak observed around $705.6 \mathrm{eV}$ corresponds to Fe in its zero-valent state [26].

The BET single point surface areas for clinoptilolite, nZVI and $3 \mathrm{Cl}$-nZVI were determined to be $16.1 \mathrm{~m}^{2} / \mathrm{g}, 21.8 \mathrm{~m}^{2} / \mathrm{g}$ and $36.1 \mathrm{~m}^{2} /$ $\mathrm{g}$, respectively. The increase in the surface area upon supporting nZVI on clinoptilolite would be expected to lead to better reactivity of the material toward dye removal.

Table 1

EDX elemental composition by weight of the main elements in each adsorbent.

\begin{tabular}{lclll}
\hline Adsorbent & Fe $\%$ & O \% & Si \% & Al \% \\
\hline Clinoptilolite & 1.17 & 57.1 & 31.0 & 5.66 \\
nZVI & 69.1 & 17.5 & NA & NA \\
1Cl-nZVI & 65.7 & 24.3 & 5.22 & 1.21 \\
2Cl-nZVI & 63.4 & 24.7 & 7.27 & 1.54 \\
3Cl-nZVI & 52.4 & 30.9 & 10.3 & 2.15 \\
5Cl-nZVI & 35.1 & 57.1 & 12.7 & 2.55 \\
3Cl-nZVI (after & 41.2 & 40.0 & 13.3 & 2.54 \\
$\quad$ dye removal) & & & & \\
\hline
\end{tabular}




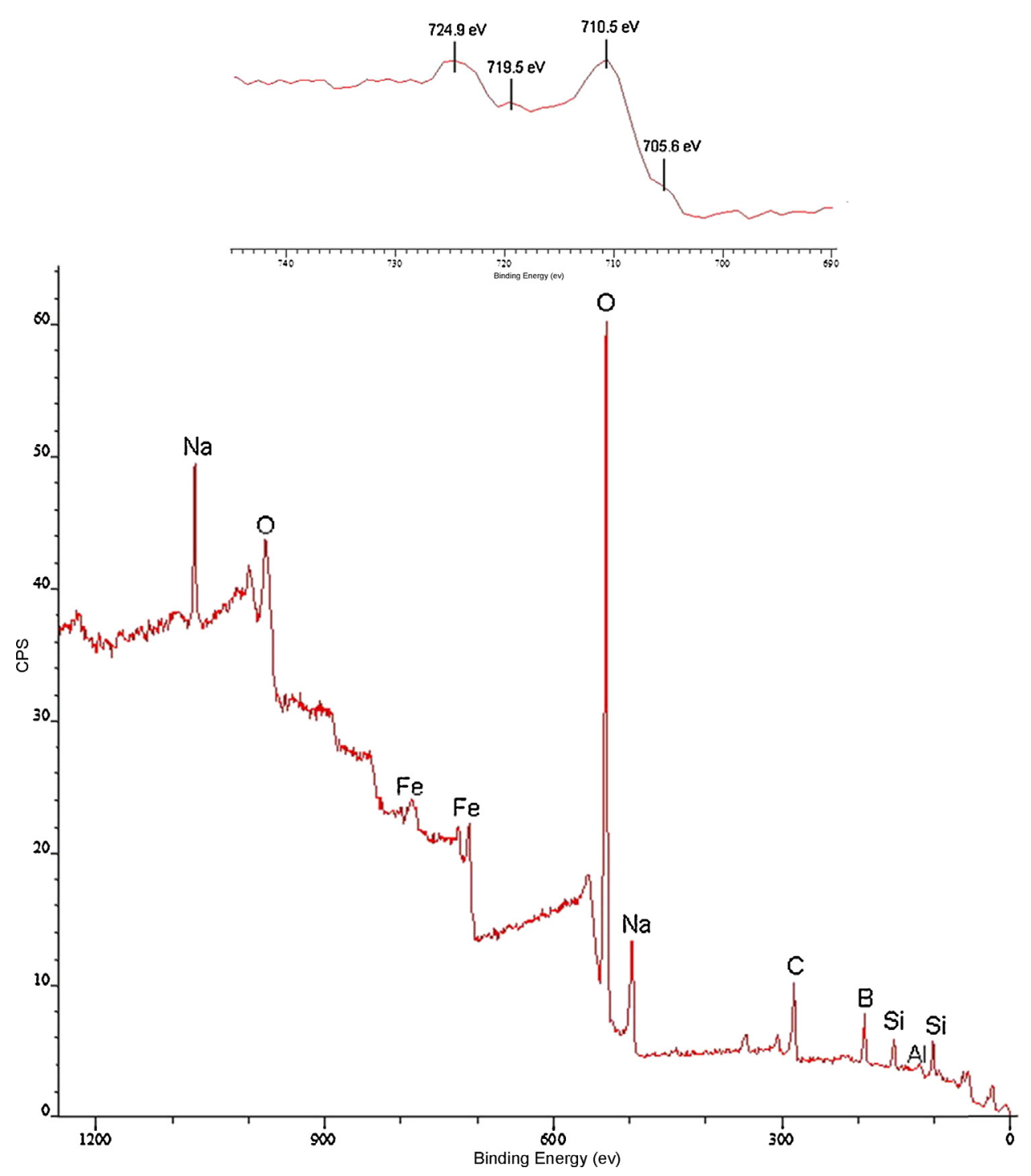

Fig. 6. XPS wide scan spectrum for $\mathrm{Cl}-\mathrm{nZVI}$ and narrow scan for Fe $2 \mathrm{p}$ feature.

MB and MO removal using clinoptilolite, nZVI and Cl-nZVI

As preliminary experiments, the MO and MB removal capacities of the four different Cl-nZVI composites were compared. The results show that the $3: 1 \mathrm{Cl}-\mathrm{nZVI}(3 \mathrm{Cl}-\mathrm{nZVI})$ showed the highest dye removal potential for both dyes. Therefore, this composite was used in all the subsequent dye removal experiments.

The dye removal kinetics of Cl-nZVI was compared with those of clinoptilolite and nZVI. The results are shown in Figs. 7A and 8A for $\mathrm{MB}$ and $\mathrm{MO}$ removal, respectively, at $100.0 \mathrm{mg} / \mathrm{L}$ initial dye concentrations. The results indicate that the $\mathrm{Cl}$-nZVI composite has faster dye removal kinetics and larger dye removal capacity when compared with both clinoptilolite and nZVI at the indicated concentration. This is attributed to the distribution of nano iron chains in-between the clinoptilolite plates, the factor that leads to decreasing the aggregation of these chains, thus making them kinetically more accessible for dye molecules, and increasing their surface area available for discoloration reaction.

The data were fitted to pseudo first order and second order kinetics. The corresponding differential rate equations can be formulated as [25]:

$\frac{d C_{t}}{d t}=k_{1}\left(C_{t}-C_{e}\right)$

$$
-\frac{d C_{t}}{d t}=k_{2}\left(C_{t}-C_{e}\right)
$$

where $C_{t}$ is the dye concentration at any given time, $C_{e}$ is the dye concentration at equilibrium, $k_{1}$ and $k_{2}$ are 1 st order and 2 nd order rate constants, respectively. Integrating both equations under boundary conditions $C_{t}=C_{0}$ at $t=0$ and $C_{t}=C_{t}$ at $t=t$ yields:

$\ln \left(\frac{C_{t}-C_{e}}{C_{0}-C_{e}}\right)=-k_{1} t$

$\frac{1}{C_{t}-C_{e}}-\frac{1}{C_{0}-C_{e}}=k_{2} t$

Eqs. (3) and (4) were employed for the pre-equilibrium data for each dye removal at the concentrations of $10.0 \mathrm{mg} / \mathrm{L}$ and $100.0 \mathrm{mg} /$ L using clinoptilolite, nZVI and Cl-nZVI, and the obtained rate constants are summarized in Table 2. The removal of MB and MO is linearly plotted using Eqs. (3) and (4) in Figs. 7B and C and 8B and C, respectively. It is clear that $\mathrm{Cl}$-nZVI demonstrated the fastest discoloration ability. On the overall, the linear correlation coefficients indicate that the second order equation is more successful in describing the discoloration data in most of the cases. Moreover, the rate constants suggest that $\mathrm{Cl}$-nZVI and nZVI can remove MB faster than $\mathrm{MO}$. 

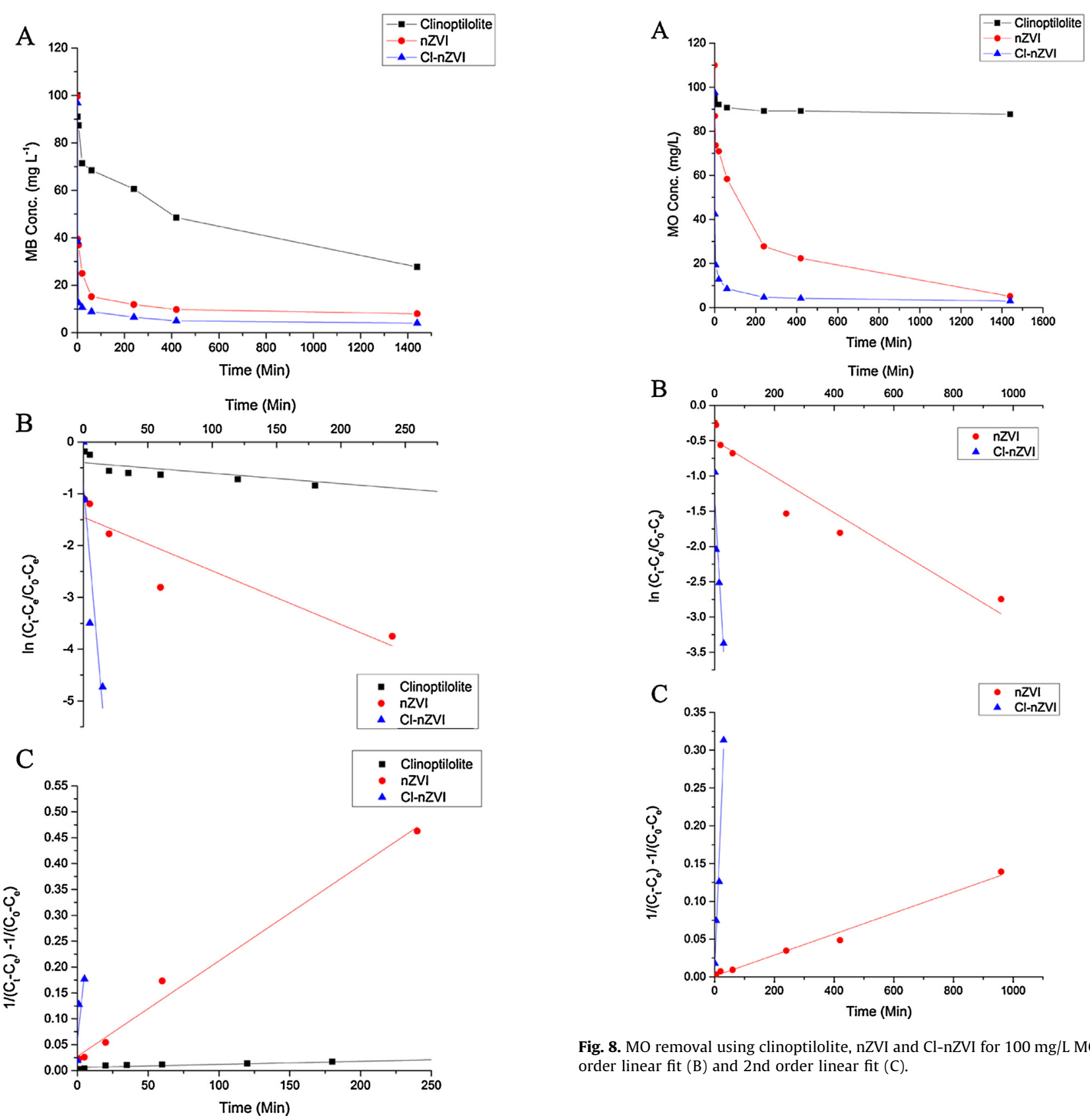

Fig. 8. MO removal using clinoptilolite, nZVI and Cl-nZVI for $100 \mathrm{mg} / \mathrm{L}$ MO (A), 1st order linear fit (B) and 2nd order linear fit (C).

Fig. 7. MB removal using clinoptilolite, nZVI and Cl-nZVI for $100 \mathrm{mg} / \mathrm{L} \mathrm{MB} \mathrm{(A),} 1 \mathrm{st}$ order linear fit (B) and 2nd order linear fit (C).

The faster cationic dye removal kinetics can be attributed to the negatively charged surface of nZVI, as monitoring the $\mathrm{pH}$ during the reduction process showed it to be ascending to around $\mathrm{pH}=9$, confirming previously reported [32] negatively charged nZVI surface. The removal of both dyes using nZVI and Cl-nZVI at $100.0 \mathrm{mg} / \mathrm{L}$ initial concentrations was more adequately described using 2nd order kinetics compared with 1 st order kinetics, as can be deduced from the $R^{2}$ values. The same conclusion can be withdrawn regarding the removal of $\mathrm{MB}$ at initial concentration of $10.0 \mathrm{mg} / \mathrm{L}$. On the other hand, the removal of $\mathrm{MO}$ at $10.0 \mathrm{mg} / \mathrm{L}$ initial concentration was adequately described using both kinetic equations using nZVI and better described using 1st order kinetics using Cl-nZVI. When comparing clinoptilolite and nZVI for the removal of $\mathrm{MB}$ using $k_{2}$ values, it can be seen that with low $\mathrm{MB}$ concentration $(10.0 \mathrm{mg} / \mathrm{L})$ the clinoptilolite showed faster dye removal. However, at high MB concentration (100.0 mg/L), nZVI

showed faster removal kinetics than clinoptilolite as can be deduced also from their $k_{2}$ values. Moreover, the MB removal at $100.0 \mathrm{mg} / \mathrm{L}$ using clinoptilolite required more than $24 \mathrm{~h}$ to achieve equilibrium with kinetics that was poorly described using any of the two kinetic equations. Based on this, it can be concluded that nZVI dye removal rate is not affected by dye concentration as much as clinoptilolite do. This could be attributed to the fact that the adsorption of MB on nZVI occurs on the outer surface of the material, while the adsorption of the dye on clinoptilolite occurs mostly on the internal pore surface of the mineral, a process that is usually controlled by pore diffusion and internal surface diffusion barriers.

As stated previously, the removal of MO using nZVI and Cl-nZVI was slower than $\mathrm{MB}$, while clinoptilolite was ineffective in showing any removal activity for MO, even at low concentrations $(10.0 \mathrm{mg} / \mathrm{L})$. This can be referred to that fact that the negatively charged surface of clinoptilolite is not accessible to the negatively charged MO molecules.

One of the prominent results of this study is the observation that the $\mathrm{Cl}-\mathrm{nZVI}$ composite has demonstrated faster removal 
Table 2

Rate constants and linear correlation coefficients corresponding to dye removal kinetic experiments realized using clinoptilolite, nZVI and Cl-nZVI.

\begin{tabular}{|c|c|c|c|c|c|c|}
\hline \multirow[t]{2}{*}{ Adsorbent } & \multirow[t]{2}{*}{ Dye conc. (mg/L) } & \multirow[t]{2}{*}{ Equilibrium time } & \multicolumn{2}{|l|}{ 1st order } & \multicolumn{2}{|l|}{ 2nd order } \\
\hline & & & $k_{1}\left(\min ^{-1}\right)$ & $R^{2}$ & $k_{2}(\mathrm{~L} /(\mathrm{mg} \min ))$ & $R^{2}$ \\
\hline \multirow{2}{*}{ Clinoptilolite } & MB 10 & $20 \mathrm{~min}$ & 0.1154 & 0.9754 & 0.1814 & 0.9950 \\
\hline & MB 100 & $>24 \mathrm{~h}$ & 0.0020 & 0.8543 & 0.0001 & 0.8929 \\
\hline \multirow[t]{4}{*}{$\mathrm{nZVI}$} & MB 10 & $4 \mathrm{~h}$ & 0.0055 & 0.9698 & 0.0024 & 0.9835 \\
\hline & MB 100 & $4 \mathrm{~h}$ & 0.0104 & 0.8427 & 0.0019 & 0.9951 \\
\hline & MO 10 & $24 \mathrm{~h}$ & 0.0010 & 0.9907 & 0.0003 & 0.9963 \\
\hline & MO 100 & $24 \mathrm{~h}$ & 0.0026 & 0.9251 & 0.0001 & 0.9892 \\
\hline \multirow[t]{4}{*}{ Cl-nZVI } & MB 10 & $15 \mathrm{~min}$ & 0.2668 & 0.9686 & 0.9953 & 0.9984 \\
\hline & MB 100 & $15 \mathrm{~min}$ & 0.2325 & 0.8307 & 0.0911 & 0.9998 \\
\hline & MO 10 & $30 \mathrm{~min}$ & 0.1927 & 0.9875 & 0.1095 & 0.9495 \\
\hline & MO 100 & $1 \mathrm{~h}$ & 0.0736 & 0.8861 & 0.0099 & 0.9793 \\
\hline
\end{tabular}

Table 3

Percentage dye removal using clinoptilolite, nZVI and Cl-nZVI at $25.0^{\circ} \mathrm{C}$.

\begin{tabular}{|c|c|c|c|c|c|c|}
\hline \multirow[t]{2}{*}{ Initial concentration $(\mathrm{mg} / \mathrm{L})$} & \multicolumn{3}{|l|}{ MB removal } & \multicolumn{3}{|l|}{ MO removal } \\
\hline & Clinoptilolite & nZVI & Cl-nZVI & Clinoptilolite & nZVI & Cl-nZVI \\
\hline 5 & 96.0 & 30.5 & 85.7 & $<1 \%$ & 39.9 & 56.6 \\
\hline 10 & 98.9 & 55.6 & 75.1 & $<1 \%$ & 83.1 & 80.3 \\
\hline 20 & 98.1 & 87.3 & 90.4 & $<1 \%$ & 88.5 & 81.6 \\
\hline 50 & 95.7 & 89.5 & 91.3 & $<1 \%$ & 91.8 & 89.9 \\
\hline 100 & 54.6 & 90.9 & 95.1 & $<1 \%$ & 91.0 & 90.5 \\
\hline 200 & 58.6 & 96.5 & 96.6 & $<1 \%$ & 90.1 & 90.2 \\
\hline
\end{tabular}

toward both of the dyes at various initial concentrations compared with individual clinoptilolite and nZVI. It can be concluded that the presence of the clinoptilolite crystals in the composite has served in decreasing the aggregation of the nZVI chains and thereby resulted in higher surface activity of the nanoparticles, and hence faster dye removal kinetics.

The effect of the initial concentration on the extent of removal of both dyes (MB and $\mathrm{MO}$ ) was studied at 5.0, 10.0, 20.0, $50.0,100.0$ and $200.0 \mathrm{mg} / \mathrm{L}$ concentrations, with each adsorbent (clinoptilolite, nZVI and Cl-nZVI) at various contact times. Table 3 summarizes the obtained results for both dyes with the three adsorbents at $25.0^{\circ} \mathrm{C}$. As can be seen, clinoptilolite showed the highest extent of removal of $\mathrm{MB}$ at low concentrations $(<50.0 \mathrm{mg} / \mathrm{L})$, while nZVI and Cl-nZVI possessed higher and almost the same extent of removal at higher MB concentrations. This suggests an enhancement in the removal ability of the mineral when nZVI is incorporated into its structure. One distinguishing characteristic of $\mathrm{Cl}-\mathrm{nZVI}$ in the removal of $\mathrm{MB}$ is its high removal potential over a wide range of concentrations, unlike any of its two components.

As obtained in the kinetic studies, it is observed that the removal of MO using clinoptilolite was negligible, even at low MO concentrations. Moreover, there was no obvious elevation in the extent of MO removal using Cl-nZVI compared with nZVI as was the case in the removal of $\mathrm{MB}$ at concentrations above $10.0 \mathrm{mg} / \mathrm{L}$. On the contrary to MB, the nZVI removal potential of MO was, to

Table 4

Percentage dye removal using nZVI and $\mathrm{Cl}$-nZVI at $50^{\circ} \mathrm{C}$.

\begin{tabular}{rlllll}
\hline Initial concentration $(\mathrm{mg} / \mathrm{L})$ & \multicolumn{2}{l}{ MB removal } & & \multicolumn{2}{c}{ MO removal } \\
\cline { 2 - 3 } & nZVI & Cl-nZVI & & nZVI & Cl-nZVI \\
\hline 5 & 56.1 & 92.8 & & 82.9 & 66.8 \\
10 & 70.6 & 95.5 & & 91.8 & 80.5 \\
20 & 78.2 & 97.3 & & 94.0 & 91.9 \\
50 & 90.3 & 92.6 & & 96.7 & 97.8 \\
100 & 95.9 & 96.5 & & 98.3 & 94.7 \\
200 & 96.6 & 96.9 & & 97.1 & 96.9 \\
\hline
\end{tabular}

some extent, higher than that of Cl-nZVI due to the fact that MO removal using nZVI is an adsorption and reduction process to sulfanilic acid, N,N-dimethyl-p-phenylenediamine and N-methylp-phenylenediamine [22]. Again, clinoptilolite has no role in the MO extent of removal, but it did pace up the kinetics of the removal process as stated previously.

The extent of removal of both dyes using nZVI and Cl-nZVI at $50.0{ }^{\circ} \mathrm{C}$ is summarized in Table 4 . A comparison between Tables 3 and 4 clearly indicates increase in both dyes removal percentages using both adsorbents at higher temperatures, hence indicating that both dyes removal process is endothermic. Higher temperature could increase the mobility of dye molecules and cause a decrease in the dye aggregation behavior, thus reducing the diffusion barrier within the solution.

The reusability study of $\mathrm{Cl}-\mathrm{nZVI}$ at $10.0 \mathrm{mg} / \mathrm{L}$ dye concentrations indicates higher dye removal potential when compared with nZVI, as detailed in Table 5. This is believed to occur due to the higher reactivity imparted to the nanoparticle chains, as the presence of clinoptilolite crystals decreased the aggregation of these chains in the solution.

The assessment of the effect of initial $\mathrm{pH}$ on both dyes removal percentages at initial concentration of $100.0 \mathrm{mg} / \mathrm{L}$ using $\mathrm{nZVI}$ and Cl-nZVI can be followed from Table 6. The table shows that the percentage removal of MB decreases slightly at elevated $\mathrm{pH}$ values. On the other side, MO demonstrated much lower percentage

Table 5

Percentage removal of MB and MO by nZVI and Cl-nZVI at successive reusability cycles. The initial dye concentration is $10.0 \mathrm{mg} / \mathrm{L}$.

\begin{tabular}{llllll}
\hline Reusability cycle & \multicolumn{2}{l}{ MB } & & \multicolumn{2}{l}{ MO } \\
\cline { 2 - 3 } \cline { 6 - 6 } & nZVI & Cl-nZVI & & nZVI & Cl-nZVI \\
\hline 1st & 49.3 & 70.5 & & 85.1 & 87.8 \\
2nd & 44.8 & 47.7 & & 80.1 & 82.9 \\
3rd & 46.1 & 84.8 & & 84.4 & 87.5 \\
4th & 49.0 & 75.8 & & 70.8 & 86.2 \\
5th & 24.0 & 62.8 & & 22.7 & 86.0 \\
6th & 8.7 & 21.6 & & 9.6 & 37.2 \\
7th & 2.6 & 13.8 & 4.3 & 17.2 \\
\hline
\end{tabular}


Table 6

Effect of initial pH on the percentage removal of MB and MO using nZVI and Cl-nZVI.

\begin{tabular}{|c|c|c|c|c|}
\hline \multirow[t]{2}{*}{ Initial $\mathrm{pH}$} & \multicolumn{2}{|l|}{ MB } & \multicolumn{2}{|l|}{ MO } \\
\hline & nZVI & Cl-nZVI & $\mathrm{nZVI}$ & Cl-nZVI \\
\hline 3 & 94.3 & 95.5 & 94.9 & 98.8 \\
\hline 5 & 97.0 & 98.4 & 95.9 & 98.1 \\
\hline 7 & 98.9 & 96.9 & 71.0 & 64.9 \\
\hline 9 & 93.3 & 81.0 & 45.5 & 30.9 \\
\hline
\end{tabular}

removal at elevated $\mathrm{pH}$ values, due to electrostatic repulsions. Moreover, compared with nZVI, Cl-nZVI seems to have higher $\mathrm{pH}$ sensitivity in its efficiency in the dye removal process as can be seen from the higher drop in the percentage removal of both dyes with the increasing $\mathrm{pH}$ values.

\section{Conclusion}

The composite sorbent of iron nanoparticles (nZVI) supported on the natural zeolite clinoptilolite (Cl-nZVI) demonstrated faster $\mathrm{MB}$ and MO dye removal kinetics compared with individual clinoptilolite and nZVI. Moreover, the Cl-nZVI composite demonstrated quantitative dye removal potential over a wide range of concentrations and demonstrated better longevity and reusability over nZVI in the removal process of both dyes.

The higher dye removal efficiency of Cl-nZVI over nZVI is attributed to the better dispersion of the iron nanoparticle chains in the presence of clinoptilolite crystals, which act as barriers between these chains. The removal process of both dyes was endothermic which means that increasing the temperature enhances the dye removal. Increasing the initial $\mathrm{pH}$ adversely affected the extent of removal of both dyes. On the overall, the material seems to fit better in the removal of the cationic MB dye than in the removal of the anionic MO dye.

\section{Conflict of interest statement}

The authors have declared no conflict of interest.

\section{Acknowledgements}

This work was financed by Birzeit University (Project No. 211006). The authors are grateful for Ministry of Innovation, Science, and Research of the German state government of NRW for their scholarship program. The authors thank Ezel Boyaci and the
Center of Materials Research at Izmir Institute of Technology for the assistance in XRD and BET analysis, and Prof. G. Wilde, Mr. M. Bühner, Mr. A. Timmer and Dr. A. Schäfer at the Center for Nanotechnology and the Physics Institute in Münster for their help in XPS, SEM, TEM and EDX analysis. The authors thank Dr. Omar Zimmo at Birzeit University for supplying the natural zeolite (clinoptilolite) samples.

\section{References}

[1] R.A. Crane, T.B. Scott, J. Hazard. Mater. 211-212 (2012) 112.

[2] D. O'Carroll, B. Sleep, M. Krol, H. Boparai, C. Kocur, Adv. Water Resour. 51 (2013) 104.

[3] D. Karabelli, Ç. Üzüm, T. Shahwan, A.E. Eroğlu, T. Scott, K. Hallam, I. Lieberwirth, Ind. Eng. Chem. Res. 47 (2008) 4758.

[4] N. Efecan, T. Shahwan, A.E. Eroğlu, I. Lieberwirth, Desalination 249 (2009) 1048.

[5] Ç. Üzüm, T. Shahwan, A.E. Eroğlu, I. Lieberwirth, T.B. Scott, K.R. Hallam, Chem. Eng. J. 144 (2008) 213.

[6] Y. Liu, S.A. Majetich, R.D. Tilton, D.S. Sholl, G.V. Lowry, Environ. Sci. Technol. 39 (2005) 1338.

[7] V. Sarathy, A.J. Salter, J.T. Nurmi, G. O’Brien Johnson, R.L. Johnson, P.G. Tratnyek, Environ. Sci. Technol. 44 (2009) 787

[8] Y.T. Wei, S.C. Wu, C.M. Chou, C.H. Che, S.M. Tsai, H.L. Lien, Water Res. 44 (2010) 131.

[9] Y.H. Hwang, D.G. Kim, H.S. Shin, J. Hazard. Mater. 185 (2011) 1513.

[10] C.-B. Wang, W.-X. Zhang, Environ. Sci. Technol. 31 (1997) 2154

[11] R. Baciocchi, M. Boni, L. D‘Aprile, Water Air Soil Pollut. 149 (2003) 211.

[12] D.W. Blowes, C.J. Ptacek, S.J. Benner, C.W. McRae, T.A. Bennett, R.W. Puls, J. Contam. Hydrol. 45 (2000) 123.

[13] K.R. Ramakrishna, T. Viraraghavan, Water Sci. Technol. 36 (1997) 189.

[14] R. Malik, D.S. Ramteke, S.R. Wate, Waste Manage. 27 (2007) 1129.

[15] M.A.M. Salleh, D.K. Mahmoud, W.A.W.A. Karim, A. Idris, Desalination 280 (2011) 1.

[16] H. Pan, J. Feng, G.X. He, C.E. Cerniglia, H. Chen, Anaerobe 18 (2012) 445.

[17] Y.S. Al-Degs, M.I. El-Barghouthi, A.H. El-Sheikh, G.M. Walker, Dyes Pigments 77 (2008) 16.

[18] G. Crini, Bioresour. Technol. 97 (2006) 1061.

[19] G. Crini, Dyes Pigments 77 (2008) 415.

[20] P. Janoš, H. Buchtová, M. Rýznarová, Water Res. 37 (2003) 4938.

[21] K. Siwińska-Stefańska, M. Nowacka, A. Kołodziejczak-Radzimska, T. Jesionowski, Dyes Pigments 94 (2012) 338.

[22] J. Fan, Y. Guo, J. Wang, M. Fan, J. Hazard. Mater. 166 (2009) 904.

[23] T. Shahwan, S. Abu Sirriah, M. Nairat, E. Boyacı, A.E. Eroğlu, T.B. Scott, K.R. Hallam, Chem. Eng. J. 172 (2011) 258.

[24] H.Y. Shu, M.C. Chang, H.H. Yu, W.H. Chen, J. Colloid Interface Sci. 314 (2007) 89.

[25] T. Shahwan, Ç. Üzüm, A.E. Eroğlu, I. Lieberwirth, Appl. Clay Sci. 47 (2010) 257.

[26] Ç. Üzüm, T. Shahwan, A.E. Eroğlu, K. Hallam, T. Scott, I. Lieberwirth, Appl. Clay Sci. 43 (2009) 172.

[27] S. Unal, A.E. Eroğlu, T. Shahwan, J. Ind. Eng. Chem. 19 (2013) 898.

[28] H. Zhang, Z.-h. Jin, L. Han, C.-h. Qin, Trans. Nonferr. Metal. Soc. 16 (2006) s345.

[29] N. Horzum, M.M. Demir, M. Nairat, T. Shahwan, RSC Adv. 3 (2013) 7828.

[30] S.A. Kim, S. Kamala-Kannan, K.-J. Lee, Y.-J. Park, P.J. Shea, W.-H. Lee, H.-M. Kim, B.T. Oh, Chem. Eng. J. 217 (2013) 54.

[31] W. Yan, A.A. Herzing, C.J. Kiely, W.X. Zhang, J. Contam. Hydrol. 118 (2010) 96.

[32] Y.P. Sun, X.Q. Li, J. Cao, W.X. Zhang, H.P. Wang, Adv. Colloid Interface Sci. 120 (2006) 47. 